\title{
Cetuximab inhibits growth, peritoneal dissemination, and lymph node and lung metastasis of endometrial cancer, and prolongs host survival
}

\author{
KAYOKO TAKAHASHI ${ }^{1,2}$, YASUSHI SAGA ${ }^{1,2}$, HIROYUKI MIZUKAMI ${ }^{2}$, YUJI TAKEI ${ }^{1,2}$, SHIZUO MACHIDA $^{1}$, \\ HIROYUKI FUJIWARA ${ }^{1}$, KEIYA OZAWA ${ }^{2}$ and MITSUAKI SUZUKI ${ }^{1}$ \\ ${ }^{1}$ Department of Obstetrics and Gynecology, and ${ }^{2}$ Division of Genetic Therapeutics, Center for Molecular Medicine, \\ School of Medicine, Jichi Medical University, Tochigi, Japan
}

Received April 27, 2009; Accepted June 25, 2009

DOI: 10.3892/ijo_00000385

\begin{abstract}
The purpose of this study was to explore the possibility of molecular-targeted therapy with anti-epidermal growth factor receptor (EGFR) antibody (cetuximab) for endometrial cancer to develop a new treatment for advanced endometrial cancer. We analyzed EGFR protein expression and gene mutations in the human endometrial cancer cell line HEC1A, and evaluated the in vitro and in vivo effects of cetuximab on HEC1A. EGFR expression was observed in HEC1A cells, but no mutations in the EGFR gene were detected. Cetuximab inhibited HEC1A cell growth and invasion and VEGF-A production in vitro, and HECIA cell tumor growth, its peritoneal dissemination with ascites, and lymph node and lung metastasis in vivo. In addition, the antibody prolonged the survival of a mouse model of systemic metastasis. These results suggest the possibility of molecular-targeted therapy using cetuximab for endometrial cancer.
\end{abstract}

\section{Introduction}

Endometrial cancer is the most commonly encountered gynecologic malignancy and the fourth most common of all malignant tumors in the United States (1). Since this cancer is often detected at an early stage when it is localized to the uterus, the overall survival rate exceeds $80 \%$ (1). However, the prognosis of advanced endometrial cancer remains poor (2). In addition to surgery, radiotherapy and multidrug chemotherapy have been attempted for advanced endometrial cancer, but no satisfactory results have been achieved. As a

Correspondence to: Dr Yasushi Saga, Department of Obstetrics and Gynecology, School of Medicine, Jichi Medical University, 3311-1 Yakushiji, Shimotsuke, Tochigi 329-0498, Japan

E-mail: saga@jichi.ac.jp

Key words: endometrial cancer, cetuximab, peritoneal dissemination, lymph node metastasis, lung metastasis result, the overall treatment results in endometrial cancer have not improved over the past 30 years (1). The most important prognostic factor for endometrial cancer is the presence or absence of extrauterine extension, including lymph node and lung metastasis, serosal invasion, and omental metastasis $(3,4)$. Therefore, to improve the prognosis of endometrial cancer, it is necessary to develop an effective therapy for such advanced cancers.

Epidermal growth factor (EGF) and epidermal growth factor receptor (EGFR) are reportedly involved in the growth and extension of malignant tumors (5). In particular, EGFR overexpression has been observed in various malignant tumors: in 40-80, 14-91, 33-74, 25-77, 30-50, 40-80, 50-90, and $36-100 \%$ of lung, breast, stomach, colon, pancreas, prostate, kidney and head and neck cancers, respectively (6). Further, EGFR overexpression has been reported to be a poor prognostic factor for various malignant tumors $(7,8)$. It has been reported that EGFR is expressed in $67 \%$ of endometrial cancers, and correlated with the disease stage, myometrial invasion, and lymph node metastasis, and EGFR-positive cancer patients have a significantly poorer prognosis than their EGFR-negative counterparts (9).

Cetuximab, an anti-EGFR monoclonal antibody, is a molecular-targeted therapeutic agent that was produced as a human-mouse chimeric antibody, has a higher binding affinity for EGFR than natural ligands and inhibits tyrosine kinase phosphorylation $(10,11)$. In addition, cetuximab reportedly induces EGFR internalization and degradation (12).

The purpose of this study was to explore the possibility of molecular-targeted therapy using anti-EGFR antibody (cetuximab) for endometrial cancer to develop a new treatment for advanced endometrial cancer.

\section{Materials and methods}

Cell culture. The human endometrial cancer cell line HEC1A (13) was kindly provided by Dr H. Kuramoto, Kitasato University. This cell line was cultured in Dulbecco's modified Eagle's medium/F12 (DMEM/F12, Gibco, Grand Island, NY) supplemented with $10 \%$ inactivated fetal calf serum, $100 \mathrm{U} / \mathrm{ml}$ of penicillin and $100 \mu \mathrm{g} / \mathrm{ml}$ of streptomycin (Gibco) at $37^{\circ} \mathrm{C}$ in a $5 \% \mathrm{CO}_{2}$ atmosphere. 
EGFR expression. EGFR expression in the HEC1A cell line was analyzed by Western blotting using anti-EGFR polyclonal antibody (Santa Cruz Biotechnology, Inc., Santa Cruz, CA).

EGFR gene mutations. The HEC1A cell line was analyzed for EGFR gene mutations. Genomic DNA was extracted from the HEC1A cell line using a QIAamp DNA mini kit (Qiagen, Valencia, CA). The hot spots (exons 18-21) of EGFR gene mutations were amplified by PCR using EX Taq (Takara, Tokyo, Japan) and primers (5'-tacacccagtggagaagc tcc-3' and 5'-ccccaccagaccatgagag-3' for exon 18, 5'-caattgcc agttaacgtcttcc-3' and 5'-ggagatgagcagggtctagag-3' for exon 19 , 5'-cacactgacgtgcctctc-3' and 5'-cttatctccctccccgta-3' for exon 20, and 5'-agggcatgaactacttg-3' and 5'-cctccttctttgcetccttc-3' for exon 21) under the following cycling conditions: for exons 18 and 19,30 cycles of $94^{\circ} \mathrm{C}$ for $30 \mathrm{sec}, 58^{\circ} \mathrm{C}$ for $30 \mathrm{sec}$, and $72^{\circ} \mathrm{C}$ for $1 \mathrm{~min}$; for exon 20,30 cycles of $94^{\circ} \mathrm{C}$ for $30 \mathrm{sec}$, $56^{\circ} \mathrm{C}$ for $30 \mathrm{sec}$, and $72^{\circ} \mathrm{C}$ for $1 \mathrm{~min}$; and for exon 21,35 cycles of $94^{\circ} \mathrm{C}$ for $30 \mathrm{sec}, 55^{\circ} \mathrm{C}$ for $30 \mathrm{sec}$, and $72^{\circ} \mathrm{C}$ for $1 \mathrm{~min}$. PCR products were separated by $0.8 \%$ agarose gel electrophoresis, purified, inserted into the pGEM-T easy vector (Promega, Madison, WI), and sequenced to confirm the presence or absence of mutations.

Anti-EGFR monoclonal antibody (cetuximab). Cetuximab was purchased from iRxMedicine Inc. (Tokyo, Japan), and used undiluted at a concentration of $2 \mathrm{mg} / \mathrm{ml}$ in all animal model experiments.

Effects of cetuximab in vitro. In all in vitro experiments, HEC1A cells were cultured in DMEM/F12 medium supplemented with $50 \mu \mathrm{g} / \mathrm{ml}$ EGF (R\&D Systems, Minneapolis, $\mathrm{MN}$ ) but not with fetal calf serum, and exposed to cetuximab at concentrations of $0-100 \mu \mathrm{g} / \mathrm{ml}$.

To examine the inhibitory effect of cetuximab on cell growth, 5,000 HEC1A cells were dispensed into the wells of 96-well plates. After $48 \mathrm{~h}$, reagents in the XTT assay Kit (Roche, Indianapolis, MA) were added, and the absorbance was measured after $24 \mathrm{~h}$.

To investigate the inhibitory effect of cetuximab on cell invasion, 10,000 HEC1A cells/well were plated in Matrigel invasion chambers (Becton-Dickinson, Bedford, MA). After $24 \mathrm{~h}$, cells invading through the membrane were stained with crystal violet to count the number of invading cells per 4 high-power fields.

To evaluate the effect of cetuximab on VEGF-A production, 5,000 HEC1A cells/well were placed in 96-well culture dishes. After $48 \mathrm{~h}$, the concentration of VEGF-A in the culture supernatant was determined using a Quantikine Human VEGF ELISA Kit (R\&D Systems).

Animal model experiments. Female 4- to 6-weeks-old nude mice (BALB/c nu, Japan Clea Laboratories, Tokyo, Japan) were used for experiments. All animal experiments were performed according to the guidelines for animal experimentation of Jichi Medical University.

To create a subcutaneous tumor model, 5x106 $\mathrm{HEC} 1 \mathrm{~A}$ cells were injected subcutaneously to form subcutaneous tumors. The tumor volume [(long diameter)x(short diameter $)^{2}$ $\left.\mathrm{X}^{1 / 2}\right]$ was measured weekly to construct tumor growth curves.

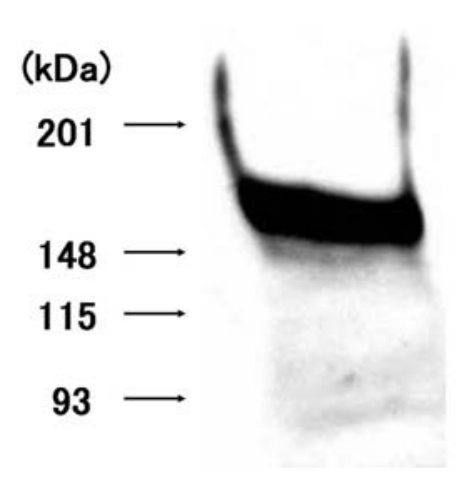

Figure 1. Western blotting using anti-EGFR polyclonal antibody. HEC1A cells expressed EGFR.

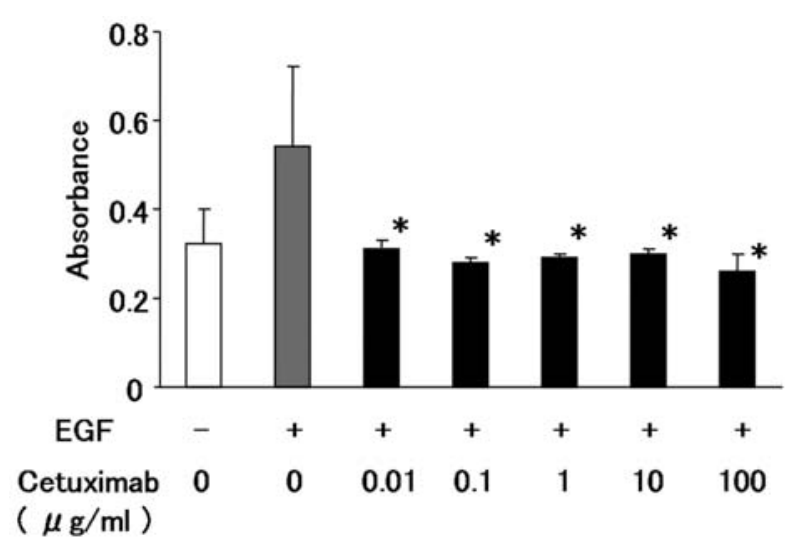

Figure 2. The number of cells $48 \mathrm{~h}$ after exposure was significantly smaller in the groups exposed to cetuximab at $0.01 \mu \mathrm{g} / \mathrm{ml}$ or higher than in the control group $\left({ }^{*} \mathrm{P}<0.05\right)$. Mean $\pm \mathrm{SD}$.

To generate a peritoneal dissemination model, $5 \times 10^{6}$ tumor cells were injected intraperitoneally into nude mice, and the number of peritoneal disseminations and volume of ascetic fluid were measured after 8 weeks.

To develop a lymph node metastasis model, $5 \times 10^{6}$ tumor cells were injected into the uterine cavity of nembutalanesthetized, laparotomized mice, and the number of enlarged lymph nodes was counted after 8 weeks.

To develop a lung metastasis model, $5 \times 10^{6}$ tumor cells were injected into the tail vein of nude mice, and the number of lung metastases was counted after 8 weeks.

To generate a systemic metastasis model, $5 \times 10^{6}$ tumor cells were injected into the peritoneal cavity and tail vein of nude mice, and the mice were observed until death. The survival of the mice was checked twice daily. Survival curves were constructed by the Kaplan-Meier method.

In each experimental model of endometrial cancer, $1 \mathrm{mg}$ of cetuximab was injected intraperitoneally twice weekly. An equal volume of phosphate-buffered saline (PBS) was used as a control.

Statistical analysis. Except for Kaplan-Meier survival curves, all differences between two groups were tested for significance by Student's t-test. Differences in Kaplan-Meier survival curves were evaluated by the log-rank test. $\mathrm{P}<0.05$ was considered significant. 


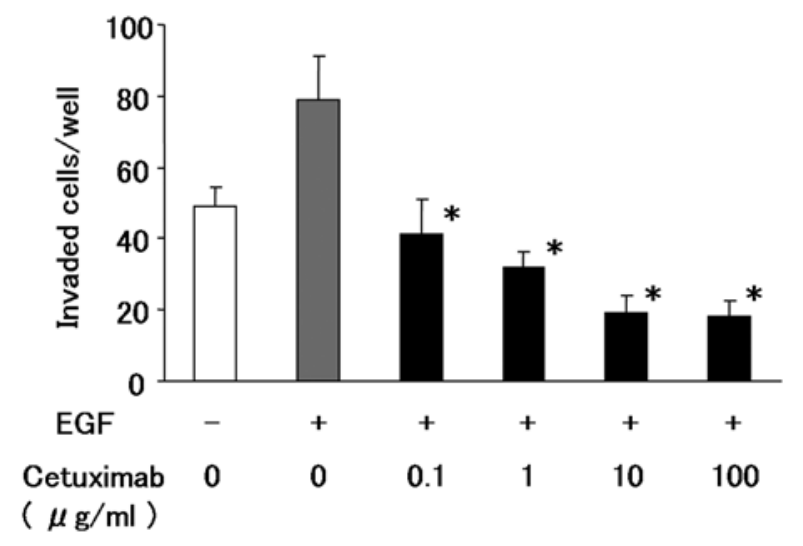

Figure 3 . The number of invading cells $48 \mathrm{~h}$ after exposure was significantly smaller in the groups exposed to cetuximab at $0.1 \mu \mathrm{g} / \mathrm{ml}$ or higher than in the control group $\left({ }^{*} \mathrm{P}<0.05\right)$. Mean $\pm \mathrm{SD}$.

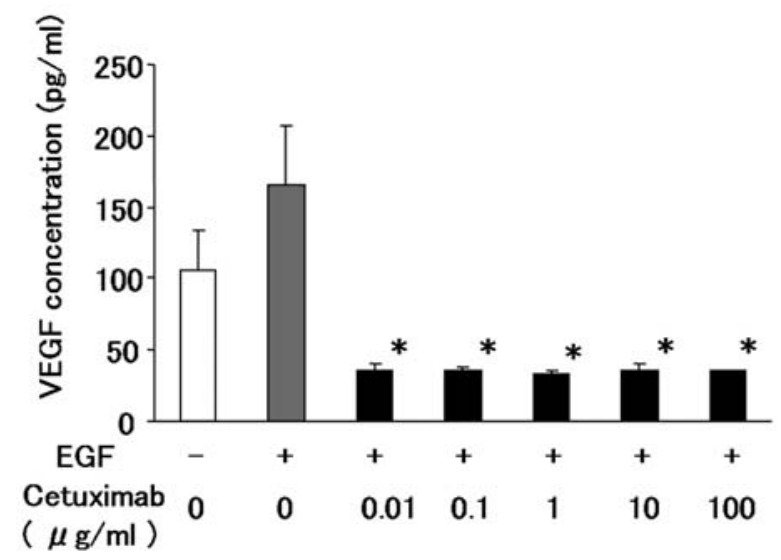

Figure 4. The concentration of VEGF-A in the culture supernatant was significantly lower in the groups exposed to cetuximab at $0.01 \mu \mathrm{g} / \mathrm{ml}$ or higher than in the control group $\left({ }^{*} \mathrm{P}<0.05\right)$. Mean $\pm \mathrm{SD}$.

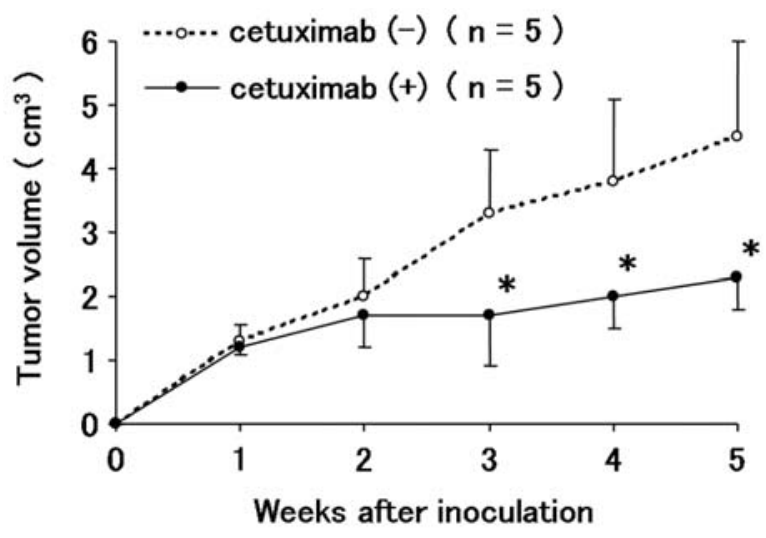

Figure 5. Subcutaneous tumor growth was significantly reduced from 3 weeks after inoculation in the cetuximab-administered group in comparison with the control group $\left({ }^{*} \mathrm{P}<0.05\right)$. Mean $\pm \mathrm{SD}$.

\section{Results}

EGFR expression. As shown in Fig. 1, EGFR expression was detected by Western blotting at the position corresponding to a molecular weight of $170 \mathrm{kDa}$ in HEC1A cells.
EGFR gene mutations. No mutations in exons 18-21 of the EGFR gene were detected in HEC1A cells.

Effects of cetuximab in vitro. Analysis of the inhibitory effect on cell growth showed that the number of cells $48 \mathrm{~h}$ after exposure was significantly smaller in the groups exposed to cetuximab at $0.01 \mu \mathrm{g} / \mathrm{ml}$ or higher than in the control group $(\mathrm{P}<0.05)$, indicating that cetuximab inhibited HEC1A cell growth (Fig. 2).

In the analysis of the inhibitory effect on cell invasion, the number of invading cells was significantly smaller in the groups exposed to cetuximab at $0.1 \mu \mathrm{g} / \mathrm{ml}$ or higher than in the control group $(\mathrm{P}<0.05)$, indicating that cetuximab inhibited HEC1A cell invasion (Fig. 3).

In the analysis of the inhibitory effect on VEGF-A production, the concentration of VEGF-A in the culture supernatant was significantly lower in the groups exposed to cetuximab at $0.01 \mu \mathrm{g} / \mathrm{ml}$ or higher than in the control group $(\mathrm{P}<0.05)$, indicating that cetuximab inhibited VEGF-A production (Fig. 4).

Animal model experiments. In the subcutaneous tumor model, tumor growth was significantly reduced from 3 weeks after inoculation in the cetuximab-administered group in comparison with the control group (Fig. 5), indicating that cetuximab inhibited HEC1A tumor growth.

In the peritoneal dissemination model, the number of peritoneal disseminations and volume of ascetic fluid 8 weeks after inoculation were significantly smaller in the cetuximabadministered group, at $3.7 \pm 2.1$ and $0.2 \pm 0.1 \mathrm{ml}$, respectively, than in the control group $(17.5 \pm 6.2$ and $4.3 \pm 5.4 \mathrm{ml}$, respectively $(\mathrm{P}<0.01$ and 0.05 , respectively), indicating that cetuximab inhibited the dissemination of HEC1A tumors and production of ascetic fluid (Figs. 6A, B, C and D).

In the lymph node metastasis model, the mean number of enlarged lymph nodes in the cetuximab-administered group 8 weeks after inoculation was $0.25 \pm 0.5$, which was significantly smaller than that $(2.0 \pm 0.0)$ in the control group $(\mathrm{P}<0.01)$, indicating that cetuximab inhibited the lymph node metastasis of HEC1A cells (Figs. 6E and F).

In the lung metastasis model, the mean number of lung metastases 8 weeks after inoculation was $3.7 \pm 0.6$ in the control group, but no lung metastases were observed in the cetuximab-administered group, indicating that cetuximab inhibited the lung metastasis of the HEC1A cells (Figs. 6G and $\mathrm{H})$.

Fig. 7 shows survival curves for the cetuximab-administered and control groups in the systemic metastasis model. In the control group, the mice began to die from the 48th day after cancer cell injection, and all had died on the 62nd day. In contrast, in the cetuximab-administered group, only two mice died, showing a significantly longer survival $(\mathrm{P}<0.01)$. Thus, cetuximab prolonged the survival of the mouse systemic metastasis model.

\section{Discussion}

In this study, we explored the possibility of molecular-targeted therapy using anti-EGFR antibody (cetuximab) for endometrial cancer to develop a new treatment for advanced endometrial cancer. 


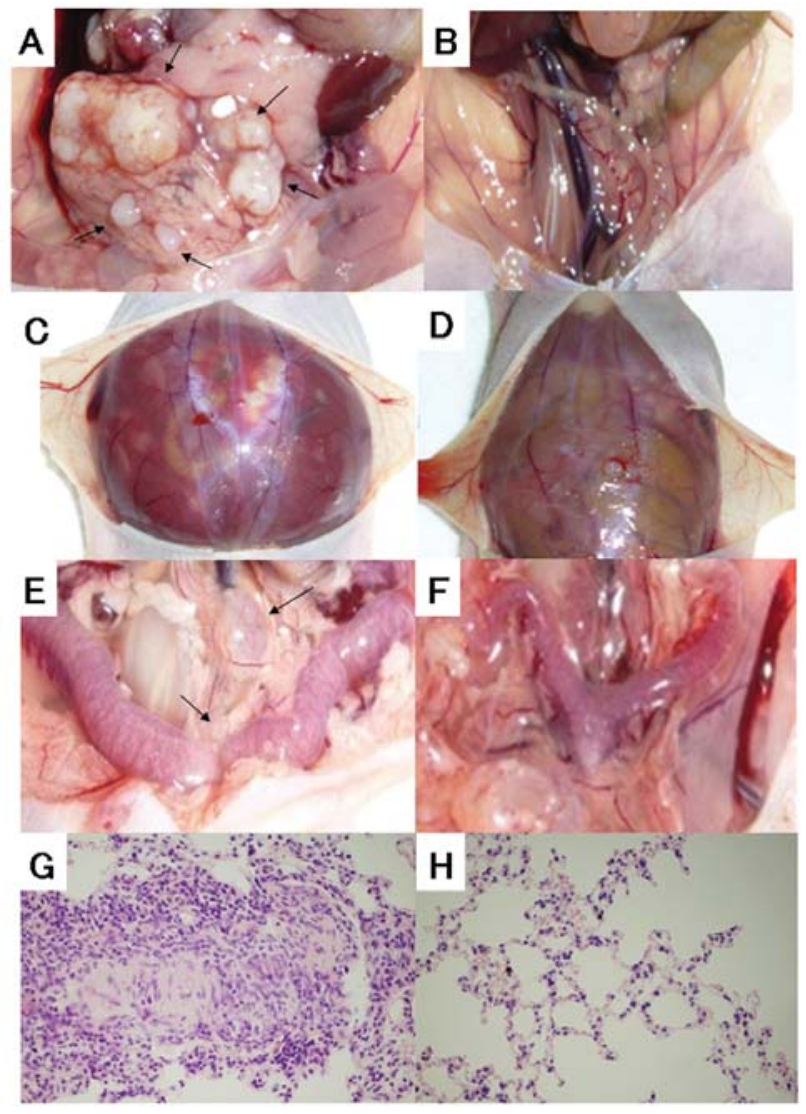

Figure 6. The number of peritoneal disseminations 8 weeks after inoculation was smaller in the cetuximab-administered group (B) than in the control group (A). The volume of ascetic fluid 8 weeks after injection was smaller in the cetuximab-administered group (D) than in the control group (C). The number of enlarged lymph nodes after 8 weeks was smaller in the cetuximabadministered group (F) than in the control group (E). Lung metastases were observed in the control group $(\mathrm{G})$, but no lung metastases were observed in the cetuximab-administered group $(\mathrm{H})$.

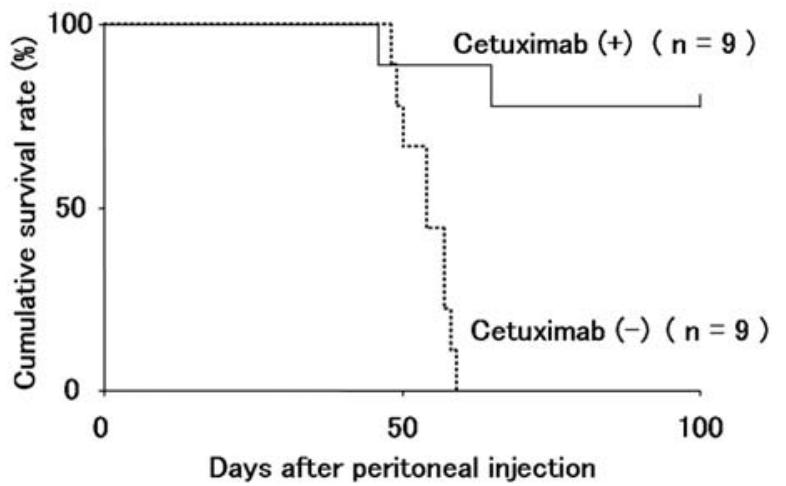

Figure 7. Survival curves for the cetuximab-administered and control groups in the systemic metastasis model. The cetuximab-administered group survived significantly longer than the control group $(\mathrm{P}<0.01)$.

As a result, cetuximab inhibited HEC1A cell growth and invasion and VEGF-A production in vitro, and HECIA-cell tumor growth, its peritoneal dissemination with ascites, and lymph node and lung metastasis in vivo. In addition, the antibody prolonged the survival of a mouse model of systemic metastasis.

Cetuximab is an anti-EGFR monoclonal antibody binding to EGFR to inhibit its activity, and it is a molecular-targeted therapeutic agent against specific molecules involved in tumor growth. It is a human-mouse chimeric antibody of the IgG1 subclass, and is clinically administered as an intravenous infusion. Currently, cetuximab has been approved by the Food and Drug Agency (FDA) as a therapeutic agent for metastatic colorectal cancer (14) and head and neck cancer (15), and used clinically.

On the other hand, there have been no reports on moleculartargeted therapy using cetuximab for endometrial cancer. The report that endometrial cancer frequently overexpresses the cetuximab-targeted EGFR (9) suggested that cetuximab would be useful in the treatment of endometrial cancer, and led to this study. As a result, cetuximab inhibited HEC1A cell growth and invasion and VEGF-A production in vitro, and HEC1A cell tumor growth, peritoneal dissemination with ascites, and lymph node and lung metastasis in vivo. In addition, the antibody prolonged the survival of a mouse model of systemic metastasis. These results suggest the possibility of molecular-targeted therapy using cetuximab for endometrial cancer.

EGFR is composed of three major domains: extracellular, transmembrane, and intracellular domains. When ligands such as EGF bind to the extracellular domain, EGFR-ligand complexes bind to other receptors to form dimers, and then the tyrosine kinase region in the intracellular domain utilizes adenosine triphosphate to phosphorylate tyrosine residues. Tyrosine phosphorylation results in the activation of intracellular signal transduction pathways, leading to the promotion of cell growth and invasion (16). EGFR was expressed in the endometrial cancer cell line HEC1A used in this study, and EGF addition promoted cell growth in vitro. These results suggest that cetuximab blocked the binding of EGF to EGFR, thereby inhibiting endometrial cancer cell growth and invasion.

On the other hand, in malignant tumors such as non-small cell lung cancer, it has been reported that mutations occur in EGFR gene exons 18-21 coding for the intracellular domain, resulting in the constitutive activation of EGFR, which is involved in malignant cell transformation (17). Currently, gefitinib $(18,19)$ and erlotinib $(20)$, which are moleculartargeting drugs specifically inhibiting EGFR tyrosine kinase activity, are reportedly effective against cancers with $E G F R$ gene mutations. However, no such mutations were detected in the endometrial cancer cell line HEC1A used, and cetuximab was effective. Further, there have been no reports of patients with endometrial cancer with EGFR gene mutations. Therefore, it is very likely that cetuximab is effective for many patients with endometrial cancer.

Cetuximab inhibited VEGF-A production in HEC1A cells, as already reported in bladder (21) and colorectal (22) cancer cells. A study in head and neck cancer cells (23) reported that the inhibition of VEGF-A production by cetuximab was mediated by EGFR. On the other hand, Luwor et al reported that the inhibitory effect of cetuximab on VEGF-A production was mediated by hypoxia-inducible factor-1 $\alpha$ (HIF-1 $\alpha)(24)$. Angiogenesis is closely involved in the progression of malignant tumors $(25,26)$. Since VEGF-A is the most important 
angiogenesis factor, the inhibition of VEGF-A production by cetuximab has the potential to inhibit angiogenesis in malignant tumors, leading to increased anti-tumor effects. In particular, in the absence of mediation by EGFR, cetuximab may be effective against EGFR-negative endometrial cancers.

Further, in animal experiments, cetuximab not only inhibited subcutaneous HEC1A tumor growth, but also peritoneal dissemination with ascites, and lymph node and lung metastasis in a model of extrauterine extension, which is a negative prognostic factor in endometrial cancer. In addition, cetuximab prolonged the survival of the systemic metastasis mouse model. These results suggest the usefulness of cetuximab in the treatment of advanced or recurrent endometrial cancer.

Few studies of molecular-targeted therapy for endometrial cancer have been reported. Molecular-targeted therapy with cetuximab for endometrial cancer, which we propose here, could be advantageous for patients with advanced or recurrent endometrial cancer, in which the prognosis has not improved for the past 30 years due to the failure to develop new treatments.

\section{References}

1. Jemal A, Siegel R and Ward E: Cancer statistics, 2008. CA Cancer J Clin 58: 71-76, 2008.

2. Wolfson AH, Sightler SE and Markoe AM: The prognostic significance of surgical staging for carcinoma of the endometrium. Gynecol Oncol 45: 142-146, 1992.

3. Lurain JR: Uterine cancer. In: Novak's Gynecology. 12th edition. Berek JS (ed). Williams \& Wilkins, Baltimore, pp1057-1077, 1996.

4. Fujiwara H, Saga Y and Takahashi K: Omental metastases in clinical stage I endometrioid adenocarcinoma. Int J Gynecol Cancer 18: 165-167, 2007.

5. Mendelsohn J and Baselga J: Status of epidermal growth factor receptor antagonists in the biology and treatment of cancer. J Clin Oncol 21: 2787-2799, 2003.

6. Normanno N, Maiello MR and De Luca A: Epidermal growth factor tyrosine kinase inhibitors (EGFR-TKIs): simple drugs with a complex mechanism of action? J Cell Physiol 194: 13-19, 2003.

7. Yamazaki H, Fukui Y and Ueyama Y: Amplification of the structurally and functionally altered epidermal growth factor receptor gene (c-erbB) in human brain tumors. Mol Cell Biol 8 : 1816-1820, 1988.

8. Hirsch FR, Varella-Garcia M and Bunn PA Jr: Epidermal growth factor receptor in non-small cell lung carcinomas: correlation between gene copy number and protein expression and impact on prognosis. J Clin Oncol 21: 3798-3807, 2003.

9. Niikura H, Sasano H and Matsunaga G: Prognostic value of epidermal growth factor receptor expression in endometrioid endometrial carcinoma. Hum Pathol 26: 892-896, 1995.

10. Kawamoto T, Sato JD and Le A: Growth stimulation of A431 cells by epidermal growth factor: identification of high affinity receptors for epidermal growth factor by an anti-receptor monoclonal antibody. Proc Natl Acad Sci USA 80: 1337-1341, 1983.
11. Masui H, Kawamoto T and Sato JD: Growth inhibition of human tumor cels in athymic mice by anti-epidermal growth factor receptor monoclonal antibodies. Cancer Res 44: 1002-1007, 1984.

12. Waksal H: Role of an anti-epidermal growth factor receptor in treating cancer. Cancer Metastasis Rev 18: 427-436, 1999.

13. Kuramoto H, Tamura S and Notake Y: Establishment of a cell line of human endometrial adenocarcinoma in vitro. Am J Obstet Gynecol 114: 1012-1019, 1972.

14. Cunningham D, Humblet Y and Siena S: Cetuximab monotherapy and cetuximab plus irinotecan in irinotecan-refractory metastatic colorectal cancer. N Engl J Med 351: 337-345, 2004.

15. Gebbia V, Giuliani F and Valori VM: Cetuximab in squamous cell head and neck carcinomas. Ann Oncol (Suppl. 6): vi5-7, 2007.

16. Scaltriti M and Baselga J: The epidermal growth factor receptor pathway: A model for targeted therapy. Clin Cancer Res 12: 5268-5272, 2006.

17. Higashiyama S, Abraham JA and Miller J: A heparin-binding growth factor secreted by macrophage-like cells that is related to EGF. Science 251: 936-939, 1991.

18. Lynch TJ, Bell DW and Sordella R: Activating mutations in the epidermal growth factor receptor underlying responsiveness of non-small-cell lung cancer to gefitinib. N Engl J Med 350: 2129-2139, 2004.

19. Choi SH, Mendrola JM and Lemmon MA: EGF-independent activation of cell-surface EGF receptors harboring mutations found in gefitinib-sensitive lung cancer. Oncogene 26: 1567-1576, 2007.

20. Pao W, Miller V and Zakowski M: EGF receptor gene mutations are common in lung cancers from 'never smokers' and are associated with sensitivity of tumors to gefitinib and erlotinib. Proc Natl Acad Sci USA 101: 13306-13311, 2004.

21. Perrotte P, Matsumoto T and Inoue K: Anti-epidermal growth factor receptor antibody C225 inhibits angiogenesis in human transitional cell carcinoma growing orthotopically in nude mice. Clin Cancer Res 5: 257-265, 1999.

22. Bruns CJ, Harbison MT and Davis DW: Antiangiogenic and antitumor activity of anti-epidermal growth factor receptor $\mathrm{C} 225$ monoclonal antibody in combination with vascular endothelial growth factor antisense oligonucleotide in human GEO colon cancer cells. Clin Cancer Res 6: 3739-3747, 2000.

23. Bancroft CC, Chen Z and Yeh J: Effects of pharmacologic antagonists of epidermal growth factor receptor, PI3K and MEK signal kinases on NF-kappaB and AP-1 activation and IL-8 and VEGF expression in human head and neck squamous cell carcinoma lines. Int J Cancer 99: 538-548, 2002.

24. Luwor RB, Lu Y and Li X: The antiepidermal growth factor receptor monoclonal antibody cetuximab/C225 reduces hypoxia-inducible factor- 1 alpha, leading to transcriptional inhibition of vascular endothelial growth factor expression. Oncogene 24: 4433-4441, 2005.

25. Folkman J: Tumor angiogenesis. Adv Cancer Res 43: 175-203, 1985.

26. Takei Y, Mizukami H and Saga Y: Suppression of ovarian cancer by muscle-mediated expression of soluble VEGFR-1/Flt-1 using adeno-associated virus serotype 1-derived vector. Int $\mathrm{J}$ Cancer 120: 278-284, 2007. 